\title{
Percursos escolares de estudantes do ensino médio de escolas públicas do município de São Leopoldo, RS: desempenho escolar, perfil e características
}

Rosangela Fritsch ${ }^{a}$ Ricardo Ferreira Vitelli ${ }^{b}$ Cleonice Silveira Rocha ${ }^{c}$ Camila Rivaldo Fensterseifer ${ }^{d}$

\section{Resumo}

No presente artigo, apresentamos resultados de uma pesquisa que teve como objetivo analisar percursos escolares de estudantes do ensino médio de escolas públicas de São Leopoldo, por meio da identificação de perfis que interferem nas desigualdades escolares, especialmente de fluxo escolar, levando à aprovação, à reprovação e ao abandono. Para isso, realizamos um estudo quantitativo com análise descritiva de dados coletados via aplicação de um questionário estruturado, usando a técnica de autoaplicação. Como suporte, utilizamos uma revisão bibliográfica e de literatura. Identificamos evidências que permitem afirmar que as diferenças de perfis associadas às características dos estudantes de escolas públicas se relacionam com a produção de desigualdades educacionais e sinalizam, além disso, situações de vulnerabilidades sociais que se reproduzem nos espaços escolares. Notamos, ainda, que, nas escolas públicas pesquisadas, há heterogeneidade de perfis de estudantes, principalmente em relação àqueles que cursam o ensino médio noturno.

Palavras-chave: Percursos escolares, Taxas de fluxo escolar, Desigualdades educacionais.

\footnotetext{
a Universidade do Vale do Rio dos Sinos, São Leopoldo, RS, Brasil.

b Universidade do Vale do Rio dos Sinos, São Leopoldo, RS, Brasil.

c Universidade do Vale do Rio dos Sinos, São Leopoldo, RS, Brasil.

d Universidade do Vale do Rio dos Sinos, São Leopoldo, RS, Brasil. 


\section{Introdução}

O presente artigo versa sobre o fracasso escolar no ensino médio, sendo resultado de uma pesquisa realizada em três escolas públicas estaduais do município de São Leopoldo, Rio Grande do Sul (RS) ${ }^{1}$. Acompanhamos o percurso escolar de estudantes ao longo de três anos, tempo previsto para a conclusão desse nível escolar, caracterizando perfis e suas interferências nas desigualdades escolares, especialmente de fluxo escolar, que levam à aprovação, à reprovação e ao abandono.

A investigação foi realizada no contexto de implantação e execução da Proposta Pedagógica do Ensino Médio Politécnico no Rio Grande do Sul, que ocorreu no segundo ano do governo de Tarso Genro (2011-2014), por intermédio da Secretaria de Educação (SEDUC). Conforme registram Ferreira e Ramos (2018, p. 1176), o "ensino médio, como uma etapa da educação básica, vem, ao longo do tempo, sendo questionado com relação às suas finalidades e, em função disso, tornou-se objeto de contínuas reformas". Essa política curricular, que teve como objetivo se constituir em um projeto progressista de esquerda, inspirado na experiência socialista do primeiro período da Revolução Soviética (FRITSCH; HEIJMANS, 2018), visava ao enfrentamento dos desafios presentes na atual conjuntura da educação brasileira, especialmente à melhoria dos índices de aprovação, reprovação, abandono e defasagem idade-série, que se apresentavam, em muitos casos, piores que os de outros Estados. Além disso, é significativo o fato de que, no documento-base da Proposta em questão, estabelece-se como prioridade a democratização da gestão, do acesso e da permanência do estudante na escola, bem como do acesso ao conhecimento com qualidade cidadã, à aprendizagem e ao patrimônio cultural, articulado com a qualificação do Ensino Médio e da Educação Profissional (RIO GRANDE DO SUL, 2011). A referida proposta pedagógica vigorou, entretanto, por apenas três anos, limitando-se a uma política de governo, que teve fim no Governo de José Ivo Sartori (2015-2018).

Diante desse contexto, nosso objetivo consistiu em caracterizar os perfis dos estudantes, analisando as relações com o seu desempenho escolar, a partir dos seguintes questionamentos: a proposta implantada no Estado do Rio Grande do Sul proporcionou melhorias nas taxas de fluxo escolar como pretendido? Existem diferenças de perfis que podem interferir no sucesso ou fracasso escolar

\footnotetext{
Essa pesquisa, intitulada "Evasão Escolar, Gestão e Formação de Recursos Humanos em Escolas Públicas de Ensino Médio no Município de São Leopoldo-RS/Brasil", dá continuidade e se mantém conectada à pesquisa "Estudo sobre a Evasão no Ensino Médio e Superior, no Município de São Leopoldo - RS", que compôs o Projeto de Pesquisa, na modalidade de Núcleo em Rede, denominado "Indicadores de Qualidade e Gestão Democrática", do Observatório de Educação, conforme edital n. ${ }^{\circ}$ 044/2010/CAPES/INEP, no período de 2011-2014. As escolas participantes foram escolhidas e incluídas na pesquisa por apresentarem, dentre as públicas, o maior número de estudantes acessando a Educação Superior em instituições de ensino local.
} 
de estudantes de escolas públicas que, historicamente, têm como público classes sociais menos favorecidas? Assim, para atingir o objetivo proposto, julgamos pertinente identificar diferenças de perfis e seus reflexos no sucesso e insucesso escolar no âmbito de escolas públicas considerando, a partir de alguns indicadores, o cenário do ensino médio no Brasil e no Rio Grande do Sul.

No que concerne a indicadores, cabe ressaltar, primeiramente, algumas incoerências mencionadas por Figueiredo et al. (2018) acerca de um desses índices, o Índice de Desenvolvimento da Educação Básica (IDEB). Entre as críticas, os autores sinalizam que o IDEB se limita às avaliações interna e externa, sem considerar questões endógenas e exógenas, que influenciam o resultado do desempenho dos estudantes:

Sendo o IDEB um instrumento que identifica se os avaliados estão assimilando as informações fornecidas pelo sistema educacional, precisaria ponderar sobre os aspectos que têm impacto direto e indireto sobre a educação, como a valorização docente, a estrutura física e a localização da escola. As diferenças socioeconômicas e culturais também deveriam influir na análise explicativa da diferença de desempenho das escolas (FIGUEIREDO et al., 2018, p. 560).

Conforme o último Censo Demográfico do Instituto Brasileiro de Geografia e Estatística (IBGE, 2011), o Brasil possui um total de 10.357.874 jovens de 15 a 17 anos. Em 2015, segundo o Censo da Educação Escolar, 8,1 milhões de estudantes estavam matriculados no ensino médio, dos quais cerca de um milhão (13\%) frequentavam a rede privada e 6,8 milhões frequentavam a rede estadual, o que equivale a $84,4 \%$ do total de matrículas e a $97,1 \%$ dos estudantes da rede pública (BRASIL, 2015). Com base nos dados dos Censos da Educação Escolar, as taxas de matrícula, apesar de pequenas oscilações a partir dos anos 2000, são representativas da melhoria significativa do acesso ao ensino médio em comparação à década de 1990, apresentando um incremento superior a 50\% nesse período.

Todavia, de acordo com Isleb (2016), as altas taxas de reprovação das escolas estaduais constituem uma grande problemática do ensino médio que precisa ser enfrentada. "Além disso, conseguir a permanência do estudante na escola, nesta etapa da Educação Básica, não necessariamente tem refletido na melhoria da aprendizagem. Do mesmo modo, a reprovação escolar não significa que o estudante não tenha aprendido" (ISLEB, 2016, p. 57).

Ao avaliar a Tabela 1, exposta a seguir, que contém as taxas de reprovação, abandono e defasagem nas escolas estaduais de ensino médio do Rio Grande do 
Sul, de 2007 a 2017, podemos perceber que todos os índices sofreram uma queda no período analisado. A taxa de abandono apresentou uma redução mais significativa que as demais taxas. Já a taxa de defasagem, que vem diminuindo ao longo do tempo, mostrou uma intensificação desse processo a partir do momento em que a presença de crianças e jovens na escola se tornou obrigatória ${ }^{2}$. Considerando especificamente o período de 2012 a 2015, observa-se que houve uma queda significativa na taxa de reprovação em 2012 em relação aos anos anteriores, a qual não se manteve, e mostrou uma curva ascendente de 2013 a 2015; as taxas de abandono e defasagem, por sua vez, exceto em 2012, período em que sofreram um leve aumento em relação aos anos anteriores, também diminuíram. Também é importante notar que houve uma piora nos resultados dos indicadores apresentados na Tabela 1 após o fim do Ensino Médio Politécnico no que diz respeito à reprovação e defasagem, sendo possível verificar redução apenas na taxa de abandono, que segue um comportamento histórico.

Ao estabelecer um comparativo entre as taxas relativas a períodos anteriores e posteriores ao Politécnico, percebem-se variações nos resultados dos indicadores. Contudo, cotejando as médias desses períodos, anterior e posterior à implantação do Politécnico, temos, respectivamente, o seguinte cenário: taxa de reprovação de $20,97 \%$ e de $17,60 \%$; taxa de abandono de $11,4 \%$ e de $9,73 \%$; e taxa de defasagem de $36,44 \%$ e de $30,05 \%$. Em todas as taxas estudadas, no período correspondente ao Ensino Médio Politécnico, os resultados médios foram mais favoráveis, ainda que a taxa de abandono siga uma tendência de redução mais ou menos constante.

Tabela 1. Evolução das taxas de reprovação, abandono e defasagem em escolas públicas estaduais, RS, 2007-2017.

\begin{tabular}{lccc}
\hline Anos & Taxa de reprovação & Taxa de abandono & Taxa de defasagem \\
\hline 2007 & 20,5 & 14,5 & 41,7 \\
2008 & 21,1 & 13,9 & 33,4 \\
2009 & 20,8 & 12,9 & 35,3 \\
2010 & 21,6 & 12,3 & 39,8 \\
2011 & 22,3 & 11,4 & 32,8 \\
2012 & 17,9 & 11,7 & 32,9 \\
2013 & 16,4 & 10,1 & 31,3 \\
2014 & 17,2 & 9,0 & 26,6 \\
2015 & 18,9 & 8,1 & 29,4 \\
2016 & 20,8 & 7,3 & 35,9 \\
2017 & 19,7 & 7,5 & 36,2 \\
\hline
\end{tabular}

Fonte: Brasil $(2015,2016,2017)$.

O Instituto Nacional de Estudos e Pesquisas Educacionais Anísio Teixeira (INEP) calcula essas taxas de acordo com o documento intitulado "Dicionário de indicadores educacionais: fórmulas de cálculo" (INEP, 2004). 
Além desses dados, que indicam taxas ainda preocupantes de reprovação, defasagem idade-série e abandono no ensino médio no RS, salientamos pesquisas acerca do fracasso escolar que vêm evidenciando algumas perspectivas importantes para a compreensão desse fenômeno. A concepção de fracasso escolar advém da noção de que os estudantes mais desfavorecidos socioculturalmente tendem a ter maiores dificuldades de aprendizado e conclusão da educação básica, decorrendo, daí, a demanda por políticas de inclusão social.

Ferraz, Neves e Nata (2018, p. 1059), por exemplo, revisaram estudos que evidenciam a relação entre as desigualdades sociais e as taxas de sucesso e insucesso escolar, acentuando que, dessa relação, "emergiu, na década de 1960, uma preocupação com o rendimento escolar de crianças de meios desfavorecidos, conduzindo ao surgimento de políticas públicas de educação orientadas para o combate ao insucesso escolar e à exclusão social". Os autores, preocupados com o impacto de programas de educação compensatória, afirmam que:

O "relatório Coleman" (COLEMAN et al., 1966) apresentar-se-á como um documento fundamental na legitimação dos programas de educação compensatória (PEC), reconhecendo a necessidade de as escolas oferecerem condições materiais e humanas que possibilitem aos estudantes igualdade de sucesso no percurso escolar, contudo, atribui maiores responsabilidades ao contexto familiar como causa principal do insucesso escolar (FERRAZ; NEVES; NATA, 2018, p. 1059).

Esse conceito de insucesso escolar começou a ser mais discutido quando Bourdieu, a partir dos anos 1960, produziu um conjunto de análises no âmbito da sociologia da educação e da cultura que vem influenciando a produção intelectual acerca da temática. A esse respeito, destacamos a afirmação expressa no livro "Escritos de Educação" (BOURDIEU, 2014, p. 55): "O capital cultural e o ethos, ao se combinarem, concorrem para definir as condutas escolares e as atitudes diante da escola, que constituem o princípio de eliminação diferencial das crianças das diferentes classes sociais". O sistema de ensino desempenha, assim, papel de destaque na reprodução de uma relação de dominação cultural, já que trata todos os educandos, por mais desiguais que sejam, de fato, como iguais em direitos e deveres.

Estudos recentes no Brasil têm averiguado os índices educacionais, procurando contextualizá-los, a fim de identificar as interferências advindas das realidades e das condições sociais, econômicas, políticas e culturais em que os estudantes vivem (BRITO, 2014; CASTRO; TAVARES JÚNIOR, 2016; FRANCESCHINI; 
MIRANDA-RIBEIRO; GOMES, 2016; FRITSCH, 2015; FRITSCH et al., 2014; FRITSCH; VITELLI; ROCHA, 2014; GARCIA et al., 2016; SILVA et al., 2016). Tais estudos, considerando o fato de que grande parte da população em idade escolar ainda não frequenta o ensino médio e de que existe um grande número de abandonos determinados por perfis específicos, apontam a necessidade de acompanhar os percursos escolares dos estudantes.

Diante disso, assumimos como pressuposto o ensino médio como educação básica e direito universal de todos e todas, balizados pela Lei n. ${ }^{\circ}$ 9.394, de 20 de dezembro de 1996, Lei de Diretrizes e Bases da Educação Nacional (LDBN) (BRASIL, 1996) e pela Emenda Constitucional n. ${ }^{\circ}$ 59, de 11 de novembro de 2009 (BRASIL, 2009). Na LDBN, explicita-se que a educação básica tem por finalidade desenvolver o educando, assegurar-lhe a formação comum indispensável para o exercício da cidadania e fornecer-lhe meios para progredir no trabalho e em estudos posteriores (BRASIL, 1996). Por sua vez, a Emenda Constitucional n. ${ }^{\circ} 59$ altera a Constituição Federal de 1988 e prolonga o tempo de escolaridade obrigatória para a faixa etária dos quatro aos 17 anos, reforçando o sentido da ampliação do direito à educação e indicando, além disso, a necessidade de assegurar o acesso, a permanência e a conclusão para todos os que se encontram na idade entre 15 e 17 anos (BRASIL, 2009). Também a Resolução n. ${ }^{\circ}$ 2, de 30 de janeiro 2012, que define as Diretrizes Curriculares Nacionais para o Ensino Médio, em seu capítulo II, que trata do referencial legal e conceitual, reafirma que o ensino médio é um direito social de cada pessoa, sendo dever do Estado garantir sua oferta pública e gratuita a todos (BRASIL, 2012).

A afirmação desses pressupostos se faz necessária no contexto atual da Lei n. ${ }^{\circ}$ 13.415, de 16 de fevereiro de 2017 (BRASIL, 2017), referente à Reforma do Ensino Médio, que emerge na conversão da Medida Provisória n. ${ }^{\circ} 746$ (BRASIL, 2016) e implica retrocessos em relação a outras legislações e políticas, como, por exemplo, o Plano Nacional de Educação (BRASIL, 2014) e o Programa Ensino Médio Inovador (BRASIL, 2011), e vai de encontro a todo um processo democrático (BRASIL, 2016). Analisando os argumentos que justificaram a edição da Medida Provisória n. ${ }^{\circ}$ 746, Ferreira e Ramos (2018, p. 1185), constatam que:

[...] o texto da MP 746 fica à margem dos pressupostos contidos no referido PNE, o que preocupa quando pensamos em uma articulação mais significativa entre esses dois documentos. Neste sentido, como garantir que a oferta de tempo integral priorizará as escolas que atendem a alunos de menor nível socioeconômico? Para promover a equidade, temos que priorizar dar mais a quem tem menos. Além disso, quais escolas seriam contempladas com esta proposta? 
Ressaltamos, ainda, que, no atual momento da realidade brasileira, não se identificam políticas públicas, programas ou ações governamentais que impactem os reflexos da questão social (CASTEL, 1998) e materializem o reconhecimento da educação como direito, observando os princípios de justiça social, qualidade, democracia e igualdade de oportunidades voltadas para a Educação Básica e que promovam o sucesso educativo.

Assim, após contextualizar e problematizar algumas nuances do ensino médio, no Brasil e no Estado do Rio Grande do Sul, apresentamos, na seção seguinte, os referenciais teórico-metodológicos que embasam este estudo. Em seguida, discorremos sobre os resultados e as discussões e, por fim, procedemos às considerações finais desta pesquisa.

\section{Referenciais teórico-metodológicos}

No trabalho investigativo, apoiamo-nos em uma revisão bibliográfica e de literatura elaborada a partir de dois conjuntos de estudos que vêm sendo desenvolvidos no Brasil. Um desses conjuntos centraliza sua atenção no ensino médio como um nível da educação básica brasileira de formação humana e cidadã e de direito universal. Os estudos que integram esse primeiro grupo discutem, fundamentalmente, as políticas educacionais no cenário contemporâneo em uma perspectiva sociológica, reconhecendo as disputas e as controvérsias que cercam a definição de políticas para essa etapa da escolarização, bem como os distintos interesses e protagonistas envolvidos (FERRETI, 2016; KRAWCZYK, 2014; MOURA; LIMA FILHO; SILVA, 2015; SILVA, 2015a, b; SILVA, 2016a,b,c).

O outro conjunto de estudos visa a compreender as desigualdades educacionais e os processos de exclusão escolar no ensino médio, assim como seus significados e suas consequências para os estudantes situados em um contexto marcado pelo projeto de sociedade capitalista dependente e desigual (ALGEBAILE, 2009; DAYRELL; JESUS, 2016; FRANCESCHINI; MIRANDA-RIBEIRO; GOMES, 2016; GOMES, 1999; PAULA, 2012; PEREIRA; LOPES, 2016; SILVA; OLIVEIRA, 2016; TOMAZETTI; SCHLICKMANN, 2016). Isso implica o desafio de reconhecer as diversidades sociopolíticas, econômicas e culturais, as questões de gênero e de pertencimento étnico-racial e as experiências vividas que interferem nos percursos escolares.

Inspiramo-nos, também, em Bourdieu e Passeron (2013), Bourdieu (2014) e Dubet $(2008,2011)$, os quais contribuem para identificar evidências que permitem inferir que as diferenças de perfis associadas às características dos estudantes de escolas públicas se relacionam com a produção de desigualdades sociais e 
educacionais e sinalizam, além disso, situações de vulnerabilidade social que se reproduzem nos espaços escolares. Bourdieu (2014) afirma que, se considerarmos as desigualdades condicionadas pela escola e pela cultura, seremos obrigados a concluir que a equidade formal intrínseca a todo o sistema escolar é, de fato, injusta: "Em toda sociedade onde se proclamam ideais democráticos, ela protege melhor os privilégios do que a transmissão aberta dos privilégios" (BOURDIEU, 2014, p. 59).

Dubet (2011, p. 289), por sua vez, chama atenção para o fato de que, comumente, se evita enfrentar o que a educação para a cidadania pode ter de paradoxal, "pois a cidadania implica a igualdade e a autonomia dos sujeitos, enquanto a educação repousa sobre a desigualdade fundamental dos mestres e dos alunos, dos adultos e das crianças". Para Dubet (2008), a escola precisa ter sentido em si mesma, sendo um espaço de convivência entre gerações e entre os próprios jovens, em vez de atuar como um mecanismo de seleção e de competição. O autor afirma, ainda, que "A educação escolar tem sempre uma dimensão ética. É preciso, portanto, que cada estudante seja reconhecido como tal, que seja tratado como um sujeito singular e igual a todos os outros, independentemente de suas performances e de seus resultados" (DUBET, 2008, p. 107).

Dubet (2008) explicita que a igualdade meritocrática das oportunidades, entretanto, permanece norteando a justiça escolar "nas sociedades democráticas, isto é, nas sociedades que consideram que todos os indivíduos são livres e iguais em princípio, mas que também admitem que esses indivíduos sejam distribuídos em posições desiguais" (DUBET, 2008, p. 11). Tal asserção nos provoca a refletir sobre o que poderia ser uma escola justa, tão justa quanto possível, ou menos injusta, o que remete a outra prerrogativa do autor, a de que a igualdade distributiva e social das oportunidades guiada pela equidade da oferta escolar e pela atenção dada aos vencidos pode se constituir em uma forma de tornar a escola menos injusta. Nesse sentido, Dubet (2008) menciona que, a fim de estabelecer uma maior igualdade na competição escolar, seria necessária uma distribuição controlada e razoável dos recursos destinados à educação pública e privada.

No que diz respeito ao delineamento metodológico, procedemos a uma revisão bibliográfica e a um estudo quantitativo, estudo este que, segundo Creswell (2010, p. 18), "avalia tendências, atitudes ou opiniões de uma população, estudando-se a mesma por meio de uma amostra ou um censo". Para formar a amostra desta pesquisa, selecionamos estudantes de forma censitária, dispensando a necessidade de realização de testes estatísticos de avaliação de significância dos resultados. Assim, foram incluídos na pesquisa 933 discentes que ingressaram no ensino médio em 2012 e que concluiriam o terceiro ano dessa etapa escolar em 2014. 
Para realizar a coleta de dados, três professoras das escolas estudadas aplicaram um questionário em sala de aula, por meio da técnica designada como autoaplicação, de modo que os pesquisados responderam ao instrumento sem a interferência de um entrevistador. Essa técnica, descrita por McDaniel e Gates (2003), permite que o entrevistado não sofra qualquer tipo de influência do entrevistador. Para que esse processo acontecesse, elaboramos um instrumento de coleta de informações composto de 45 questões fechadas sobre o perfil social, econômico, acadêmico e familiar dos estudantes ingressantes. Após a aplicação do instrumento, as professoras de cada escola inseriram os dados coletados em planilhas eletrônicas, os quais foram posteriormente agrupados e analisados.

Para o desenvolvimento deste artigo, selecionamos dados referentes a 12 questões do instrumento, utilizando como critério variáveis que se mostraram relevantes em pesquisas anteriores já referidas neste estudo. Além da aplicação do instrumento, levantamos e inserimos em planilhas eletrônicas, ao final de cada ano letivo, o registro da situação escolar dos estudantes feito pelas professoras que aplicaram o instrumento, a qual poderia ser: abandono, aprovado, reprovado e transferido. A partir dessas informações, os discentes foram agrupados de acordo com os perfis específicos identificados e descritos a seguir.

\section{Resultados e discussões}

As informações coletadas durante os anos de 2012, 2013 e 2014 foram analisadas, gerando oito tipos de perfis de estudantes, representados pelas letras A até $\mathrm{H}$, conforme explicita a Tabela 2.

Tabela 2. Distribuição dos perfis dos estudantes ao final do terceiro ano do ensino médio (2014).

\begin{tabular}{lcc}
\hline Perfis & Quantidade Absoluta & Quantidade Relativa (\%) \\
\hline A & 297 & 31,8 \\
B & 4 & 0,5 \\
C & 16 & 1,7 \\
D & 47 & 5,0 \\
E & 242 & 25,9 \\
F & 146 & 15,6 \\
G & 24 & 2,7 \\
H & 157 & 16,8 \\
Total & 933 & 100,0 \\
\hline
\end{tabular}

Fonte: elaborada pelos autores (2017) 
A descrição dos perfis é apresentada, a seguir, na Tabela 3, em que a situação de cada estudante foi avaliada ao final do período analisado neste estudo, o que permitiu agrupá-los de acordo com essa situação.

Conforme os dados da Tabela 3, a cada dez estudantes que ingressaram no primeiro ano do ensino médio em 2012, apenas três concluíram essa etapa escolar no período previsto. Além disso, os estudantes retidos em qualquer um dos três anos - perfis B a D - somam 7,2\% da amostra, e o fato de a taxa de retenção final ficar maior a cada ano relaciona-se ao aumento do abandono escolar. Tais informações indicam que as constantes reprovações levam o estudante a abandonar a escola.

Especificamente quanto ao abandono, os estudantes dos perfis $\mathrm{E}$ a $\mathrm{G}$, que deixaram a escola em algum dos três anos do ensino médio, totalizam 44,2\% dos discentes. Essa taxa não corresponde às taxas anuais de abandono escolar, apresentadas pelas escolas, mas, sim, à taxa de abandono do ensino médio por turma de ingressantes avaliada. Esse indicador, ainda que não consista em um indicador educacional oficial, deve ser observado, pois avalia a trajetória dos estudantes e permite entender com maior amplitude o fenômeno em questão.

Já os estudantes que foram transferidos para outra escola, em qualquer momento e por qualquer motivo (grupo H), representam 16,8\% dos alunos. Dessa forma, ao final de três anos, $31,8 \%$ concluíram o ensino médio, e $68,2 \%$ solicitaram transferência, abandonaram a escola ou ficaram retidos pelo caminho, indicando a gravidade e intensidade do fracasso escolar.

Tabela 3. Descrição dos oito tipos de perfis identificados no estudo.

\begin{tabular}{llc}
\hline Perfis & \multicolumn{1}{c}{ Descrição dos perfis } & $\%$ \\
\hline A & $\begin{array}{l}\text { Estudantes que não obtiveram nenhuma reprovação durante os três anos } \\
\text { do ensino médio, concluindo essa etapa no tempo previsto. }\end{array}$ & 31,8 \\
B & $\begin{array}{l}\text { Estudantes que foram reprovados em todos os anos, continuando, em } \\
\text { 2014, retidos no primeiro ano do ensino médio. }\end{array}$ & 0,5 \\
C & $\begin{array}{l}\text { Estudantes que foram reprovados no primeiro ou no segundo ano, } \\
\text { estando retidos, em 2014, no segundo ano do ensino médio. }\end{array}$ & 1,7 \\
D & $\begin{array}{l}\text { Estudantes que foram reprovados no terceiro ano, estando retidos, em } \\
\text { 2014, no terceiro ano do ensino médio. }\end{array}$ & 5,0 \\
E & $\begin{array}{l}\text { Estudantes que não saíram do primeiro ano e que, ao final do período } \\
\text { avaliado, abandonaram a escola. }\end{array}$ & 25,9 \\
F & $\begin{array}{l}\text { Estudantes que estavam retidos no segundo ano e que abandonaram a escola. } \\
\text { Estudantes que estavam retidos no terceiro ano e que abandonaram a escola. }\end{array}$ & 15,6 \\
H & $\begin{array}{l}\text { Estudantes que, em algum momento dos três períodos, obtiveram } \\
\text { transferência para outra escola. }\end{array}$ & 16,8 \\
\hline
\end{tabular}

Fonte: elaborada pelos autores. (2017) 
No que concerne ao turno de estudo (manhã, tarde e noite), a Tabela 4 demonstra a situação dos 933 pesquisados, de acordo com os oito perfis de alunos já identificados. É importante destacar que os dados numéricos não devem ser comparados tendo como base uma mesma coluna, pois partem de quantidades totais diferentes, mas uma mesma linha.

De acordo com os dados da Tabela 4, podemos observar que os estudantes da manhã se concentram no perfil A - discentes que concluíram o ensino médio. Já os estudantes da noite se concentram no perfil $\mathrm{E}$ - alunos que não saíram do primeiro ano e que, ao final do período analisado, abandonaram a escola. Os estudantes classificados como perfil D, ou seja, aqueles retidos no terceiro ano do ensino médio, são predominantemente da manhã e da tarde.

Analisando os mesmos perfis, agora distribuídos pela situação de emprego e estudo dos pesquisados (Tabela 5), percebemos que os estudantes que apenas estudam se situam preponderantemente no perfil $\mathrm{A}$, enquanto que os que estudam e trabalham se concentram no perfil E. Já os estudantes que estudam e fazem estágio se dividem entre os perfis A e E. Dessa forma, é possível notar que o emprego - ou até mesmo o estágio, embora em menor proporção - interfere no desempenho escolar dos estudantes. O emprego, mantido muito provavelmente para garantir condições básicas de sobrevivência e de um padrão de consumo desejado, parece, assim, apresentar-se como prioridade em detrimento da escola. Tal situação é agravada pelo fato de que, com o ensino médio incompleto, esses jovens se inserem no mercado de trabalho em empregos precários, que não estimulam o retorno à escola ou a continuidade dos estudos.

Outro aspecto avaliado na pesquisa e apresentado na Tabela 6, exposta a seguir, concerne à situação anterior ao ingresso dos estudantes no ensino médio.

Tabela 4. Distribuição percentual dos perfis por turno de estudo ${ }^{3}$.

\begin{tabular}{lccccccccc}
\hline Turno & A & B & C & D & E & F & G & H & Total \\
\hline Manhã & $63,3 \%$ & $50,0 \%$ & $68,8 \%$ & $44,7 \%$ & $36,4 \%$ & $48,6 \%$ & $45,8 \%$ & $38,9 \%$ & 453 \\
Tarde & $25,3 \%$ & $50,0 \%$ & $25,0 \%$ & $42,6 \%$ & $22,7 \%$ & $14,4 \%$ & $33,3 \%$ & $35,7 \%$ & 241 \\
Noite & $11,4 \%$ & - & $6,2 \%$ & $12,7 \%$ & $40,9 \%$ & $37,0 \%$ & $20,9 \%$ & $25,4 \%$ & 239 \\
Total & 297 & 4 & 16 & 47 & 242 & 146 & 24 & 157 & 933 \\
\hline
\end{tabular}

Fonte: elaborada pelos autores. (2017)

\footnotetext{
3 Nesta e nas demais tabelas, as células assinaladas em cinza indicam maior concentração de respostas. As informações percentuais destacadas levam em consideração uma amostra significativa de dados; caso contrário, o valor percentual pode ser elevado, mas a base de cálculo é pequena. Os percentuais foram obtidos por colunas.
} 
Os resultados mostram que os estudantes que, antes de ingressarem no ensino médio, cursaram o ensino fundamental, seja na mesma escola ou não, concentraram-se no perfil A, enquanto que os estudantes oriundos da Educação de Jovens e Adultos (EJA) e os que permaneceram um tempo sem estudar ficaram aglomerados no perfil E. Além desses dados, é importante atentarmos ao fato de que os discentes que nunca foram reprovados no ensino fundamental (Tabela 7), em sua maioria, igualmente não foram reprovados no ensino médio. Contudo, aqueles que já tinham histórico de reprovação no ensino fundamental também foram, em grande parte, reprovados no ensino médio e/ou abandonaram a escola.

Ressaltamos, ainda, a relação entre a situação dos estudantes e a presença de filhos. Embora apenas 18 estudantes afirmassem ter filhos, esse aspecto fez diferença na constituição dos perfis elaborados (Tabela 8): aqueles que declararam ter filhos

Tabela 5. Distribuição dos perfis por situação de emprego e de estudo.

\begin{tabular}{lcccccccc}
\hline Situação & A & B & C & D & E & F & G & H \\
\hline Apenas estuda & 220 & 3 & 14 & 34 & 119 & 95 & 13 & 101 \\
Estuda e trabalha & 57 & 1 & 1 & 11 & 101 & 42 & 8 & 42 \\
Estuda e faz estágio & 20 & - & 1 & 2 & 22 & 9 & 3 & 14 \\
Total & 297 & 4 & 16 & 47 & 242 & 146 & 24 & 157 \\
\hline
\end{tabular}

Fonte: elaborada pelos autores. (2017)

Tabela 6. Distribuição dos perfis com base na situação anterior ao ingresso no ensino médio.

\begin{tabular}{lcccccccc}
\hline Anteriormente... & A & B & C & D & E & F & G & H \\
\hline Cursou ensino fundamental na mesma escola & 79 & 2 & 4 & 3 & 22 & 30 & 3 & 21 \\
Cursou ensino fundamental em outra escola & 214 & 2 & 12 & 43 & 175 & 110 & 21 & 130 \\
Cursou Educação de Jovens e Adultos (EJA) & - & - & - & - & 34 & 6 & - & 4 \\
Ficou um tempo sem estudar & 4 & - & - & 1 & 11 & - & - & 2 \\
Total & 297 & 4 & 16 & 47 & 242 & 146 & 24 & 157 \\
\hline
\end{tabular}

Fonte: elaborada pelos autores. (2017)

Tabela 7. Distribuição dos perfis por situação de aprovação no ensino fundamental

\begin{tabular}{lcccccccc}
\hline No ensino fundamental... & A & B & C & D & E & F & G & H \\
\hline Nunca reprovou & 210 & 2 & 8 & 31 & 68 & 55 & 11 & 69 \\
Reprovou pelo menos uma vez & 87 & 2 & 8 & 16 & 174 & 91 & 13 & 88 \\
Total & 297 & 4 & 16 & 47 & 242 & 146 & 24 & 157 \\
\hline
\end{tabular}

Fonte: elaborada pelos autores. (2017) 
se concentraram no perfil E, ao passo que os demais, no perfil A. Associado à presença de filhos, está o fato de que esses estudantes apresentavam uma idade média maior do que aqueles que não tinham filhos.

Outro fator avaliado foi o grau de instrução dos pais. Na Tabela 9, os resultados dos perfis são segmentados conforme esse dado, indicando que os estudantes concentrados no perfil E são filhos de pais com baixa escolaridade, enquanto que os filhos de pais com ensino fundamental completo ou algum nível superior de ensino se concentram no perfil A.

Por outro lado, quando considerado o grau de instrução da mãe (Tabela 10), percebemos que filhos de mães com ensino fundamental e/ou médio incompleto se dividem entre os perfis A e E.

Considerando a relação entre o acesso à internet e o perfil dos estudantes (Tabela 11), podemos notar que tal elemento não parece não ter influenciado a constituição dos perfis, já que, em ambos os casos, os estudantes concentraramse no perfil A.

Tabela 8. Distribuição dos perfis com base na presença ou ausência de filhos.

\begin{tabular}{lcccccccc}
\hline Possui filhos & A & B & C & D & E & F & G & H \\
\hline Sim & 1 & - & - & - & 14 & 1 & - & 2 \\
Não & 296 & 4 & 16 & 47 & 228 & 145 & 24 & 155 \\
Total & 297 & 4 & 16 & 47 & 242 & 146 & 24 & 157 \\
\hline
\end{tabular}

Fonte: elaborada pelos autores. (2017)

Tabela 9. Distribuição dos perfis conforme o grau de instrução do pai.

\begin{tabular}{lcccccccc}
\hline Grau de instrução do pai & A & B & C & D & E & F & G & H \\
\hline Não sei & 54 & - & 5 & 11 & 70 & 38 & 4 & 35 \\
Analfabeto & 3 & - & - & 1 & 6 & 2 & - & 3 \\
Ensino fundamental incompleto & 85 & 3 & 5 & 13 & 83 & 55 & 10 & 46 \\
Ensino fundamental completo & 32 & - & 3 & 6 & 28 & 8 & 1 & 12 \\
Ensino médio incompleto & 19 & - & 1 & 5 & 11 & 9 & 1 & 13 \\
Ensino médio completo & 71 & 1 & 2 & 11 & 33 & 23 & 6 & 36 \\
Ensino superior incompleto & 7 & - & - & - & 4 & 2 & - & 5 \\
Ensino superior completo & 20 & - & - & - & 7 & 6 & 2 & 3 \\
Pós-graduação & 6 & - & - & - & - & 3 & - & 4 \\
Total & 297 & 4 & 16 & 47 & 242 & 146 & 24 & 157 \\
\hline Fonn
\end{tabular}

Fonte: elaborada pelos autores. (2017) 
Uma das questões do instrumento aplicado dizia respeito à quantidade de livros que os estudantes possuíam em casa (Tabela 12). Os estudantes que possuíam livros se concentraram no grupo dos que concluíram o ensino médio sem reprovação, enquanto que os que não possuíam livros compuseram o perfil dos reprovados no primeiro ano e evadidos da escola.

Outro questionamento da pesquisa abordava aos motivos que levaram os estudantes a escolherem a escola em que cursariam o ensino médio (Tabela 13). É interessante

Tabela 10. Distribuição dos perfis conforme o grau de instrução da mãe.

\begin{tabular}{lcccccccc}
\hline Grau de instrução da mãe & A & B & C & D & E & F & G & H \\
\hline Não sei & 33 & - & 3 & 3 & 45 & 15 & 2 & 19 \\
Analfabeta & 4 & - & - & 2 & 2 & 1 & - & 3 \\
Ensino fundamental incompleto & 112 & 2 & 6 & 20 & 115 & 63 & 8 & 57 \\
Ensino fundamental completo & 32 & - & 4 & 3 & 24 & 16 & 4 & 15 \\
Ensino médio incompleto & 19 & 1 & 3 & 6 & 19 & 18 & 4 & 19 \\
Ensino médio completo & 55 & 1 & - & 13 & 31 & 22 & 2 & 36 \\
Ensino superior incompleto & 15 & - & - & - & - & 5 & 2 & 1 \\
Ensino superior completo & 17 & - & - & - & 5 & 5 & 2 & 4 \\
Pós-graduação & 10 & - & - & - & 1 & 1 & - & 3 \\
Total & 297 & 4 & 16 & 47 & 242 & 146 & 24 & 157 \\
\hline
\end{tabular}

Fonte: elaborada pelos autores. (2017)

Tabela 11. Distribuição dos perfis com base no acesso à internet.

\begin{tabular}{lcccccccc}
\hline Possui acesso à internet & A & B & C & D & E & F & G & H \\
\hline Sim & 232 & 2 & 14 & 40 & 216 & 107 & 23 & 137 \\
Não & 65 & 2 & 2 & 7 & 26 & 39 & 1 & 20 \\
Total & 297 & 4 & 16 & 47 & 242 & 146 & 24 & 157 \\
\hline
\end{tabular}

Fonte: elaborada pelos autores. (2017)

Tabela 12. Distribuição dos perfis conforme a quantidade de livros presente em casa.

\begin{tabular}{lcccccccc}
\hline Quantidade de livros & A & B & C & D & E & F & G & H \\
\hline Menos de 10 livros & 69 & 1 & 4 & 10 & 59 & 35 & 5 & 43 \\
De 11 a 20 livros & 94 & 2 & 3 & 20 & 64 & 43 & 4 & 43 \\
De 21 a 50 livros & 43 & - & 2 & 1 & 30 & 19 & 3 & 13 \\
Mais de 50 livros & 30 & - & 2 & 6 & 13 & 19 & 2 & 16 \\
Não sei dizer & 51 & 1 & 5 & 7 & 58 & 25 & 8 & 35 \\
Não possuo livros & 10 & - & - & 3 & 18 & 5 & 2 & 7 \\
Total & 297 & 4 & 16 & 47 & 242 & 146 & 24 & 157 \\
\hline
\end{tabular}

Fonte: elaborada pelos autores. (2017) 
observar que os motivos relacionados à decisão da família, à proximidade com a residência e à qualidade do ensino foram significativos na composição do perfil A.

O instrumento utilizado também questionou os estudantes sobre a existência de algum tempo, além dos horários de aula, dedicado aos estudos (Tabela 14). A esse respeito, é importante destacar que os alunos que completaram o ensino médio sem reprovação foram aqueles que disponibilizaram horários para estudo fora da sala de aula.

Outro aspecto a ser considerado é a relação com a taxa de defasagem idade-série, indicador que corresponde aos estudantes com mais de dois anos de idade do que a estabelecida para a série cursada e apresenta relevância na constituição dos perfis dos discentes (FRITSCH et al., 2014). Os perfis dos alunos analisados neste estudo, levando em consideração a defasagem idade-série no momento de ingresso no ensino médio, são expostos a seguir na Tabela 15. Ao observar os

Tabela 13. Distribuição dos perfis conforme o motivo de escolha da escola frequentada.

\begin{tabular}{lcccccccc}
\hline Motivo de escolha da escola & A & B & C & D & E & F & G & H \\
\hline Não escolhi, foram meus pais & 43 & 2 & 4 & 8 & 32 & 26 & 1 & 25 \\
Já estudava nessa escola & 19 & - & 3 & 1 & 19 & 8 & 1 & 5 \\
Por ser próxima de minha casa & 87 & - & 2 & 13 & 72 & 42 & 6 & 39 \\
Por ser próxima do meu trabalho/estágio & 1 & - & - & - & 4 & 1 & - & - \\
Por ter vaga disponível & 16 & - & 1 & 1 & 28 & 16 & 5 & 25 \\
Pela qualidade do ensino & 85 & 1 & 3 & 10 & 34 & 31 & 6 & 41 \\
Por ter vaga no horário & 8 & 1 & 1 & 1 & 9 & 5 & - & 4 \\
Por escolha da Secretaria de Educação & 16 & - & - & 5 & 16 & 6 & 3 & 11 \\
Por ter um amigo ou parente que estudava aqui & 17 & - & 2 & 8 & 17 & 9 & 2 & 4 \\
Outro motivo & 5 & - & - & - & 11 & 2 & - & 3 \\
Total & 297 & 4 & 16 & 47 & 242 & 146 & 24 & 157 \\
\hline
\end{tabular}

Fonte: elaborada pelos autores. (2017)

Tabela 14. Distribuição dos perfis conforme o estudo fora da sala de aula.

\begin{tabular}{lcccccccc}
\hline Estuda fora dos horários de aula & A & B & C & D & E & F & G & H \\
\hline Sim & 203 & 3 & 12 & 31 & 96 & 98 & 16 & 88 \\
Não sinto necessidade & 46 & - & 2 & 5 & 31 & 10 & 3 & 19 \\
Não tenho tempo disponível & 16 & - & 1 & 5 & 73 & 22 & 4 & 28 \\
Prefiro fazer outras coisas & 32 & 1 & 1 & 6 & 42 & 16 & 1 & 22 \\
Total & 297 & 4 & 16 & 47 & 242 & 146 & 24 & 157 \\
\hline
\end{tabular}

Fonte: elaborada pelos autores. (2017) 
Tabela 15. Distribuição dos perfis por defasagem idade-série.

\begin{tabular}{lcccccccc}
\hline Em defasagem idade-série & A & B & C & D & E & F & G & H \\
\hline Sim & 50 & 1 & 1 & 4 & 76 & 43 & 6 & 34 \\
Não & 247 & 3 & 15 & 43 & 166 & 103 & 18 & 123 \\
Total & 297 & 4 & 16 & 47 & 242 & 146 & 24 & 157 \\
\hline
\end{tabular}

Fonte: elaborada pelos autores. (2017)

dados, notamos que os estudantes com defasagem idade-série se concentraram no perfil daqueles com reprovações e abandono escolar. Essas duas taxas aumentam quando os discentes estão em defasagem escolar. Por outro lado, os estudantes com a idade recomendada para a série concentraram-se, principalmente, no perfil dos aprovados em todos os anos do ensino médio.

Diante dos dados coletados, podemos afirmar que a relação verificada entre os perfis dos estudantes e as situações de desempenho escolar se aproximam dos resultados de pesquisas anteriores, mencionadas neste artigo, com destaque para as investigações de Dayrell e Jesus (2016) e Franceschini, Miranda-Ribeiro e Gomes (2016). Como avanço deste estudo, ressaltamos a constatação de que, nas escolas públicas pesquisadas, há diversos perfis de estudantes, especialmente em relação àqueles que cursam o ensino médio noturno. Tais achados evidenciam que, nas escolas públicas que abrigam, sobretudo, estudantes de classes menos favorecidas, a questão social apresenta características próprias: percebem-se realidades distintas em termos de desigualdades sociais e escolares.

\section{Considerações finais}

Este estudo buscou compreender, de uma forma mais ampla, fatores relacionados com os percursos escolares dos estudantes de ensino médio de três escolas públicas do município de São Leopoldo. O ensino médio, conforme Enguita (2014, p. 10), "foi e é, há muito tempo, a encruzilhada estrutural do sistema educativo", entrelaçando-se, ainda, organicamente com outras encruzilhadas, conforme evidências identificadas a partir das relações entre as características dos estudantes e o seu desempenho escolar.

A maior parte dos discentes se concentrou em dois tipos de perfil: o perfil A, constituído de estudantes que foram aprovados em todos os anos do ensino médio, concluindo essa etapa no período de tempo indicado; e o perfil E, formado pelos estudantes que foram reprovados no primeiro ano e abandonaram a escola. Esses dois perfis englobaram quase $70 \%$ dos estudantes, demonstrando que o aspecto da reprovação é tão importante que pode definir a permanência do estudante na escola. 
Ademais, as características associadas às maiores chances de reprovação e abandono escolar detectadas neste estudo foram: estudar no período noturno, trabalhar ou estagiar, ter ficado um tempo sem estudar ou ter cursado EJA, ter sido reprovado pelo menos uma vez no ensino fundamental, ter filhos, ser filho de pai com baixo grau de instrução, não possuir livros em casa, não ter escolhido a escola por razões como qualidade e proximidade da casa, não dedicar tempo aos estudos fora dos horários de aula e estar em defasagem idade-série. Observamos, porém, que esses não são fatores determinísticos, uma vez que estudantes nessas condições também conseguem aprovação, indo ao encontro do que constatam Castro e Tavares Júnior (2016) de que o background familiar, embora influencie, não determina o sucesso escolar. Identificamos, ainda, que os estudantes com aprovação nos três anos e, portanto, com conclusão do ensino médio no tempo previsto contam com melhores condições extraclasse, as quais contribuem para a maior probabilidade de continuidade dos seus estudos.

Diante disso, cabe ressaltar que propostas curriculares com interesses ideológicos e partidários, como foi o caso da Proposta Pedagógica do Ensino Médio Politécnico no Rio Grande do Sul, mesmo que bem-intencionadas, não constituem uma política de estado, o que nos leva a concordar com Krawczyk (2011) e Silva e Oliveira (2016), quando analisam as políticas educacionais e elucidam alguns avanços sem, contudo, desconsiderar os enormes desafios para a expansão, a universalização, a democratização e a massificação do ensino em nível médio. Para Silva e Oliveira (2016, p. 24),

a evasão, a crise de legitimidade da escola, a identidade do Ensino Médio (ou melhor, a ausência dela), os embates em torno do currículo, os sentidos atribuídos pelos jovens à escola, a utilidade social dos diplomas, as novas demandas de formação dos docentes, a relação dos jovens com as tecnologias, as condições de infraestrutura, as condições de gestão escolar, a questão em torno do resgate da escola enquanto instituição cultural, as especificidades e demandas do Ensino Médio noturno e os investimentos públicos são atualmente os principais desafios desta etapa de escolaridade.

Algebaile (2009) sustenta que a ampliação do sistema de ensino, a partir dos anos 1990, foi embasada no entendimento de que a educação consiste em um fator minimizador de riscos e de tensões sociais e que, a fim de atender a essa concepção, utiliza-se a estrutura da rede de escolas públicas para atenuar a pobreza. Neste estudo, identificamos evidências que permitem afirmar que as diferenças de perfis associadas às características dos estudantes de escolas públicas se relacionam com 
a produção de desigualdades educacionais e sinalizam, além disso, situações de vulnerabilidades sociais que se reproduzem nos espaços escolares. Em uma mesma escola pública, notamos heterogeneidade de perfis de estudantes. Nesse sentido, as condições desiguais de que partem os estudantes nos permitem corroborar a crítica da lógica da igualdade meritocrática das oportunidades formulada por Dubet (2008), para quem o projeto de construir uma escola justa, ou o menos injusta possível, leva a articular e a combinar vários princípios de justiça. Dentre estes, o autor destaca a proteção e a garantia a todo cidadão de uma cultura comum e o domínio sobre os efeitos sociais das desigualdades escolares, afirmando que, ante o reconhecimento de uma crueldade intrínseca da competição meritocrática, a educação deve formar os indivíduos independentemente de suas performances e de seus méritos (DUBET, 2008).

A esse respeito, Kuenzer (2010) explicita que universalizar o ensino médio com qualidade social pressupõe ações que visem à inclusão de todos no processo educativo, com garantia de acesso, permanência e conclusão de estudos; com respeito e atendimento à diversidade socioeconômica, cultural, de gênero, étnica, racial e de acessibilidade, promovendo igualdade de direitos; e com desenvolvimento da gestão democrática. Diante disso, reforçamos a pertinência de políticas sociais de inclusão, isto é, políticas de ação afirmativa, como estratégia para amenizar as desigualdades sociais na perspectiva de uma escola menos injusta. Por outro lado, tendo em vista a complexidade do fenômeno das desigualdades sociais e educacionais, que são expressões da questão social, e tomando como referência o estudo de Ferraz, Neves e Nata (2018), faz-se necessário lembrar os limites de programas de educação compensatória no domínio de resultados escolares. 


\title{
School trajectories of high school students of public schools in the municipality of Sao Leopoldo, RS: school performance, profile and characteristics
}

\begin{abstract}
In this academic paper, we show the results of a research whose objective was to analyze school trajectories of high school students of public schools in the municipality of São Leopoldo, through the identification of profiles that interfere in the school inequalities, especially concerning the school flow, leading to school approval, repetition and evasion. For this, we performed a quantitative study with descriptive analysis of data collected by a self-applied structured questionnaire. Bibliographical and literature reviews were used as support. We have identified evidence that allows us to affirm that the differences of profiles associated with the characteristics of public school students are related to the production of educational inequalities and that also indicates situations of social vulnerability reproduced in the school spaces. In the public schools surveyed there are heterogeneity and diversity of student profiles, especially in relation to those who attend high school at night.
\end{abstract}

Keywords: School trajectories, School flow rates, Educational inequalities.

\section{Recorridos escolares de estudiantes de enseñanza secundaria de escuelas públicas del municipio de São Leopoldo, RS: desempeño escolar, perfil y características}

\section{Resumen}

En el presente artículo, presentamos resultados de una investigación que tuvo como objetivo analizar itinerarios escolares de estudiantes de enseñanza secundaria de escuelas públicas de São Leopoldo, por medio de la identificación de perfiles que interfieren en las desigualdades escolares, especialmente de flujo escolar, llevando a la aprobación, reprobación y el abandono. Para ello, realizamos un estudio cuantitativo con análisis descriptivo de datos recolectados a través de la aplicación de un cuestionario estructurado, usando la técnica de auto aplicación. Como soporte, utilizamos una revisión bibliográfica $y$ de literatura. Identificamos evidencias que permiten afirmar que las diferencias de perfiles asociadas a las características de los estudiantes de escuelas públicas se relacionan con la producción de desigualdades educativas y señalan además situaciones de vulnerabilidades sociales que se reproducen en los espacios escolares. En el caso de las escuelas públicas investigadas, hay heterogeneidad de perfiles de estudiantes, principalmente en relación a aquellos que cursan la enseñanza secundaria nocturna.

Palabras clave: Recorridos escolares, Tasas de flujo escolar, Desigualdades educativas. 


\section{Referências}

ALGEBAILE, E. Escola pública e pobreza: a ampliação para menos. Rio de Janeiro: Lamparina/Faperj, 2009.

BOURDIEU, P. Escritos da educação. Petrópolis: Vozes, 2014.

BOURDIEU, P.; PASSERON, J. C. Os herdeiros: os estudantes e a cultura. Florianópolis: Editora da UFSC, 2013.

BRASIL. Emenda Constitucional Nº. 59, de 11 de novembro de 2009. Acrescenta $\S 3^{\circ}$ ao art. 76 do Ato das Disposições Constitucionais Transitórias para reduzir, anualmente, a partir do exercício de 2009, o percentual da Desvinculação das Receitas da União incidente sobre os recursos destinados à manutenção e desenvolvimento do ensino de que trata o art. 212 da Constituição Federal, dá nova redação aos incisos I e VII do art. 208, de forma a prever a obrigatoriedade do ensino de quatro a dezessete anos e ampliar a abrangência dos programas suplementares para todas as etapas da educação básica, e dá nova redação ao $\S 4^{\circ}$ do art. 211 e ao $\S 3^{\circ}$ do art. 212 e ao caput do art. 214, com a inserção neste dispositivo de inciso VI. Diário Oficial da União, 12 nov. 2009.

. Lei $\mathrm{N}^{\circ}$ 9.394, de 20 de dezembro de 1996. Estabelece as diretrizes e bases da educação nacional. Diário Oficial da União, 23 dez. 1996.

. Lei $\mathrm{N}^{\mathrm{o}} 13.005$, de 25 de junho de 2014. Aprova o Plano Nacional de Educação - PNE e dá outras providências. Diário Oficial da União, 26 jun. 2014.

BRASIL. Lei $\mathrm{N}^{\mathrm{o}} 13.415$, de 16 de fevereiro de 2017. Altera as Leis $\mathrm{n}^{\mathrm{o}} \mathrm{s}$ 9.394, de 20 de dezembro de 1996, que estabelece as diretrizes e bases da educação nacional, e 11.494, de 20 de junho 2007, que regulamenta o Fundo de Manutenção e Desenvolvimento da Educação Básica e de Valorização dos Profissionais da Educação, a Consolidação das Leis do Trabalho - CLT, aprovada pelo Decreto-Lei $n^{0} 5.452$, de $1^{\circ}$ de maio de 1943, e o Decreto-Lei $\mathrm{n}^{\mathrm{o}} 236$, de 28 de fevereiro de 1967; revoga a Lei ${ }^{\circ} 11.161$, de 5 de agosto de 2005; e institui a Política de Fomento à Implementação de Escolas de Ensino Médio em Tempo Integral. Diário Oficial da União, 17 fev. 2017.

Medida provisória $\mathrm{N}^{\mathrm{o}} 746$, de 22 de setembro de 2016. Institui a Política de Fomento à Implementação de Escolas de Ensino Médio em Tempo 
Integral, altera a Lei ${ }^{\circ}$ 9.394, de 20 de dezembro de 1996, que estabelece as diretrizes e bases da educação nacional, e a Lei no 11.494 de 20 de junho 2007, que regulamenta o Fundo de Manutenção e Desenvolvimento da Educação Básica e de Valorização dos Profissionais da Educação, e dá outras providências. Diário Oficial da União, 23 set. 2016.

. Ministério da Educação. Portal Brasileiro de Dados Abertos. Microdados do censo escolar: 2010, 2011, 2012, 2013, 2014, 2015, 2016, 2017. Brasília, DF, 2015. Disponível em:< http://dados.gov.br/dataset/ microdados-do-censo-escolar>. Acesso em: 15 dez. 2016.

. Ministério da Educação. Conselho Nacional de Educação. Resolução CNE No 2, de 30 de janeiro 2012. Define Diretrizes Curriculares Nacionais para o Ensino Médio. Disponível em: <https:/goo.gl/SY1QIf $>$. Acesso em: 27 mar. 2016.

. Ministério da Educação. Programa Ensino Médio inovador: documento orientador. Brasília, DF, 2011. Disponível em: <https://goo.gl/ XoPLp0>. Acesso em: 9 maio 2016.

BRITO, M. M. A. A dependência na origem: desigualdades no sistema educacional brasileiro e a estruturação social as oportunidades. 2014. $270 \mathrm{f}$. Tese (Doutorado em Sociologia) — Universidade de São Paulo, São Paulo, 2014.

CASTEL, R. As metamorfoses da questão social: uma crônica do salário. Petrópolis: Vozes, 1998.

CASTRO, V. G.; TAVARES JÚNIOR, F. Jovens em contextos sociais desfavoráveis e sucesso escolar no ensino médio. Educação \& Realidade, Porto Alegre, v. 41, n. 1, p. 239-58, 2016. https://doi.org/10.1590/2175-623656080

CRESWELL, J. W. Projeto de pesquisa: métodos qualitativo, quantitativo e misto. 3. ed. Porto Alegre: Artmed, 2010.

DAYRELL, J. T.; JESUS, R. E. Juventude, ensino médio e os processos de exclusão escolar. Educação \& Sociedade, Porto Alegre, v. 37, n. 135, p. 40723, 2016. https://doi.org/10.1590/ES0101-73302016151533

DUBET, F. Mutações cruzadas: a cidadania e a escola. Revista Brasileira de Educação, Rio de Janeiro, v. 16, n. 47, p. 289-306, 2011. https://doi.org/10.1590/S1413-24782011000200002 
DUBET, F. O que é uma escola justa? A escola de oportunidades. São Paulo: Cortez, 2008.

ENGUITA, M. F. Prefácio: A encruzilhada da instituição escolar. In: KRAWCZYK, N. Sociologia do ensino médio: crítica ao economicismo na política educacional. São Paulo: Cortez, 2014. p. 7-11.

FERRAZ, H.; NEVES, T.; NATA, G. A eficácia dos programas de educação compensatória nos resultados escolares: análise do programa nacional português de educação compensatória ao longo de 13 anos. Ensaio: Avaliação e Políticas Públicas em Educação, Rio de Janeiro, v. 26, n. 100, p. 1058-83, 2018. https://doi.org/10.1590/s0104-40362018002601036

FERREIRA, R. A.; RAMOS, L. O. L. O projeto da MP No 746: entre o discurso e o percurso de um novo ensino médio. Ensaio: Avaliação e Políticas Públicas em Educação, Rio de Janeiro, v. 26, n. 101, p. 1176-96, 2018. https://doi.org/10.1590/s0104-40362018002601295

FERRETI, C. J. Reformulações do ensino médio. Holos, Natal, v. 32, n. 6, p. 71-91, 2016.

FIGUEIREDO, D. et al. Os cavalos também caem: tratado das inconsistências do IDEB. Ensaio: Avaliação e Políticas Públicas em Educação, Rio de Janeiro, v. 26, n. 100, p. 552-72, 2018. https://doi.org/10.1590/s0104-403620180026001178

FRANCESCHINI, V.; MIRANDA-RIBEIRO, P.; GOMES, M. M. F. A cor da reprovação: fatores associados à reprovação dos alunos do ensino médio. Educação e Pesquisa, São Paulo, v. 42, n. 3, p. 773-86, 2016. https://doi.org/10.1590/S1517-9702201609149965

FRITSCH, R. (Org.). Ensino médio: caminhos e descaminhos da evasão escolar. São Leopoldo: Oikos, 2015.

FRITSCH, R. et al. Para que jovens? Que políticas?- perfil de alunos ingressantes no ensino médio e políticas educacionais. In: DORE, R. et al. Evasão na educação: estudos, políticas e propostas de enfrentamento. Brasília, DF: Editora do IFB/RIMEPES, 2014. p. 133-64.

FRITSCH, R.; HEIJMANS, R. D. O "novo paradigma da politecnia" na experiência do ensino médio politécnico no Rio Grande do Sul. Educação Unisinos, São Leopoldo, v. 22, n. 2, p. 194-203, 2018. 
FRITSCH, R.; VITELLI, R.; ROCHA, C. S. Defasagem idade-série em escolas estaduais de ensino médio do Rio Grande do Sul. Revista Brasileira de Estudos Pedagógicos. Brasília, v. 95, n. 239, p. 218-36, 2014. https://doi.org/10.1590/S2176-66812014000100012

GARCIA, P. S. et al. O ensino médio nos municípios do grande ABC Paulista: análise e interpretação de alguns indicadores de desempenho. Revista Iberoamericana de Evaluación Educativa, Madri, v. 9, n. 2, p. 167-89, 2016. https://doi.org/10.15366/riee2016.9.2.009

GOMES, C. A. Sucesso e fracasso no ensino médio. Ensaio: Avaliação e Políticas Públicas em Educação, Rio de Janeiro, v. 7, n. 24, p. 259-80, 1999.

INSTITUTO BRASILEIRO DE GEOGRAFIA E ESTATÍSTICA - IBGE. Censo demográfico 2010: características gerais da população: resultados da amostra. Rio de Janeiro, 2011. Disponível em: <https://ww2.ibge.gov.br/home/ estatistica/populacao/censo2010/default.shtm>. Acesso em: 2 dez. 2017.

INSTITUTO NACIONAL DE ESTUDOS E PESQUISAS EDUCACIONAIS ANÍSIO TEIXEIRA - INEP. Dicionário de indicadores educacionais: fórmulas de cálculo. Brasília, DF, 2004. Disponível em: <http://portal.inep. gov.br/documents/186968/484154/Dicion\%C3\%A1rio+de+Indicadores+Edu cacionais $+\mathrm{f} \% \mathrm{C} 3 \% \mathrm{~B} 3 \mathrm{rmulas}+\mathrm{de}+\mathrm{c} \% \mathrm{C} 3 \%$ A1lculo/bf7eac55-d33b-42a7-8d542d70fa4e24a3?version=1.2>. Acesso em: $19 \mathrm{dez} .2018$.

ISLEB, V. Ensino Médio Inovador (ProEMI): adesão inicial e monitoramento dos dados do fluxo escolar. In: SILVA, M. R. (Org.). O Ensino Médio: suas políticas, suas práticas - estudos a partir do Programa Ensino Médio Inovador. Curitiba: UFPR/Setor de Educação, 2016. p. 49-68.

KRAWCZYK, N. Reflexão sobre alguns desafios do ensino médio no Brasil hoje. Cadernos de Pesquisa, São Paulo, v. 41, n. 144, p. 752-69, 2011. https://doi.org/10.1590/S0100-15742011000300006

. Sociologia do Ensino Médio: crítica ao economicismo na política educacional. São Paulo: Cortez, 2014.

KUENZER, A. Z. O ensino médio no Plano Nacional de Educação 2011-2020: superando a década perdida? Educação \& Sociedade, Campinas, v. 31, n. 112, p. 851-73, 2010. https://doi.org/10.1590/S0101-73302010000300011

McDANIEL, C.; GATES, R. Pesquisa de marketing. São Paulo: Pioneira, 2003. 
MOURA, D. H.; LIMA FILHO, D. L. ; SILVA, M. R. Politecnia e formação integrada: confrontos conceituais, projetos políticos e contradições históricas da educação brasileira. Revista Brasileira de Educação, Rio de Janeiro, v. 20, n. 63, p. 1057-80, 2015. https://doi.org/10.1590/S1413-24782015206313

PAULA, S. G. Desigualdades e desempenho escolar no processo de escolarização da juventude: uma análise contextual sobre a expansão do ensino médio na região metropolitana de Belo Horizonte. 2012. $370 \mathrm{f}$. Tese (Doutorado em Educação) - Universidade Federal de Minas Gerais, Belo Horizonte, 2012.

PEREIRA, B. P.; LOPES, R. E. Por que ir à Escola? Os sentidos atribuídos pelos jovens do ensino médio. Educação \& Realidade, Porto Alegre, v. 41, n. 1, p. 193-216, 2016. https://doi.org/10.1590/2175-623655950

RIO GRANDE DO SUL. Secretaria Estadual de Educação. Proposta pedagógica para o ensino médio politécnico e educação profissional integrada ao ensino médio 2011-2014. Porto Alegre: Secretaria Estadual de Educação, 2011.

SILVA, M. R. Currículo, ensino médio e BNCC: um cenário de disputas. Revista Retratos da Escola, Brasília, v. 9, n. 17, p. 367-79, 2015 a.

SILVA, M. R. Direito à educação, universalização e qualidade: cenários da Educação Básica e da particularidade do Ensino Médio. Jornal de Políticas Educacionais, Curitiba, v. 9, n. 17-18, p. 61-74, 2015 b.

. (Org.). O Ensino Médio: suas políticas, suas práticas: estudos a partir do Programa Ensino Médio Inovador. Curitiba: Editora da UFPR, 2016A.

. O programa ensino médio inovador como política de indução a mudanças curriculares: da proposta enunciada a experiências relatadas. Educação em Revista, Belo Horizonte, v. 32, n. 2, p. 91-110, $2016 \mathrm{~B}$.

. Políticas educacionais para o Ensino Médio e sua gestão no Brasil contemporâneo. Dialogia, São Paulo, v. 23, p. 17-29, 2016c. https://doi.org/10.5585/dialogia.N24.6813

SILVA, M. R.; OLIVEIRA, R. G. (Orgs.). Juventude e ensino médio: sentidos e significados da experiência escolar. Curitiba: Editora da UFPR, 2016.

SILVA, P. B. C. et al. Sobre o sucesso e o fracasso no Ensino Médio em 15 anos (1999 e 2014). Ensaio: Avaliação e Políticas Públicas em Educação, Rio de Janeiro, v. 24, n. 91, p. 445-76, 2016. https://doi.org/10.1590/S0104-40362016000200009 
TOMAZETTI, E. M.; SCHLICKMANN, V. Escola, ensino médio e juventude: a massificação de um sistema e a busca de sentido. Educação e Pesquisa, São Paulo, v. 42, n. 2, p. 331-42, 2016. https://doi.org/10.1590/S1517-9702201606139017

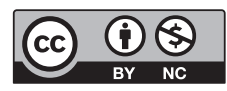

Rosangela Fritsch: Professora titular na UNISINOS nos Programas de Pós-Graduação em Educação (Acadêmico) e em Gestão Educacional (Profissional), na Graduação e em Especializações da mesma universidade. Doutora em Educação pela UNISINOS. Mestre em Serviço Social pela Pontifícia Universidade Católica do Rio Grande do Sul, Brasil. Graduada em Serviço Social pela Pontifícia Universidade Católica do Rio Grande do Sul, Brasil. Contato: rosangelaf@unisinos.br

iD https://orcid.org/0000-0002-0630-3649

Ricardo Ferreira Vitelli: Professor adjunto na UNISINOS. Doutor em Educação, Mestre em Educação e Especialista em Metodologia do Ensino Superior, todos pela mesma universidade. Graduado em Estatística pela Universidade Federal do Rio Grande do Sul (UFRGS).Contato: vitelli@unisinos.br

iD https://orcid.org/0000-0002-8023-9163

Cleonice Silveira Rocha: Professora na Graduação e Lato Sensu da UNISINOS. Doutora em Educação pela mesma universidade. Mestre em Ergonomia pela Universidade Federal do Rio Grande do Sul. Especialista em Gestão de Pessoas e Graduada em Serviço Social pela UNISINOS. Contato: nice@unisinos.br

ID https://orcid.org/0000-0001-6219-9615

Camila Rivaldo Fensterseifer: Bolsista de Iniciação Científica do curso de Engenharia Química na UNISINOS. Contato: camila.fensterseifer@gmail.com

iD https://orcid.org/0000-0002-2729-9407 